\title{
Endovascular Repair for Kommerell's Diverticulum and Right-Sided Aortic Arch
}

\author{
Kei Kazuno, MD and Seiichiro Murata, MD
}

\begin{abstract}
A 74-year-old man with hoarseness was diagnosed with a right-sided aortic arch and Kommerell's diverticulum by computed tomography (CT). The diverticulum had a maximum diameter of $33 \mathrm{~mm}$, and surgical intervention was chosen because of the possibility of rupture. A right common carotid to right subclavian artery bypass was constructed, stent-graft was placed after the branching of the right common carotid artery, and coil embolization of the diverticulum was performed via left brachial artery. No leaks were found on postoperative CT. Symptoms disappeared and the diverticulum became smaller soon after surgery. Thoracic endovascular aortic repair (TEVAR) for Kommerell's diverticulum was safe and effective.
\end{abstract}

Keywords: TEVAR, Kommerell's diverticulum, right-sided aorta

\section{Introduction}

Right-sided aortic arch with Kommerell's diverticulum is relatively rare and often treated by thoracotomy, ${ }^{1)}$ but recent improvement in the reported outcomes of stent grafting have led to increasing use. ${ }^{2)}$ However, anomalous branching of the cervical carotid artery and a steep angle of the aortic arch may necessitate a change of therapeutic strategy. We report our experience with a patient for whom stent grafting with cervical debranching and chimney technique was successful.

\section{Case Report}

A 74-year-old man presented with hoarseness and swallowing difficulty. A physical examination revealed Kommerell's diverticulum and a right-sided aortic arch that were considered as associated with the symptoms because no other abnormalities were found. Contrast computer-

Department of Cardio-Vascular Surgery, Itabashi chuo Medical Hospital, Tokyo, Japan

Received: May 10, 2016; Accepted: November 25, 2016 Corresponding author: Kei Kazuno, MD. Department of CardioVascular Surgery, Itabashi chuo Medical Hospital, 2-12-7 Azusawa, Itabashi-ku, Tokyo 174-0051, Japan

Tel: +81-3-3967-1181, Fax: +81-3-3967-0572

E-mail: kazuno@asahikawa-med.ac.jp ized tomography (CT) confirmed the right-sided aortic arch and cervical branching in the following order: left common carotid artery; right common carotid artery; right subclavian artery; and left subclavian artery. The left subclavian artery originated from the descending aorta near the top of the aortic arch, and the base region was enlarged to a maximum diameter of $33 \mathrm{~mm}$, forming Kommerell's diverticulum (Fig. 1). As echocardiography revealed no evidence of intracardiac anomaly, the diagnosis was a Kommerell's diverticulum associated with an Edwards type IIIb right-sided aortic arch.

The patient had subjective symptoms and a history of hypertension. Considering the risk of further enlargement and rupture of the diverticulum, stent grafting with cervical debranching and chimney graft technique was performed. Surgery was performed under general anesthesia with the patient in the supine position. After administration of heparin 6000 units, a right common carotid artery to right subclavian artery bypass was constructed using a blood vessel prosthesis $\left(\mathrm{Gelsoft}^{\circledR}\right.$

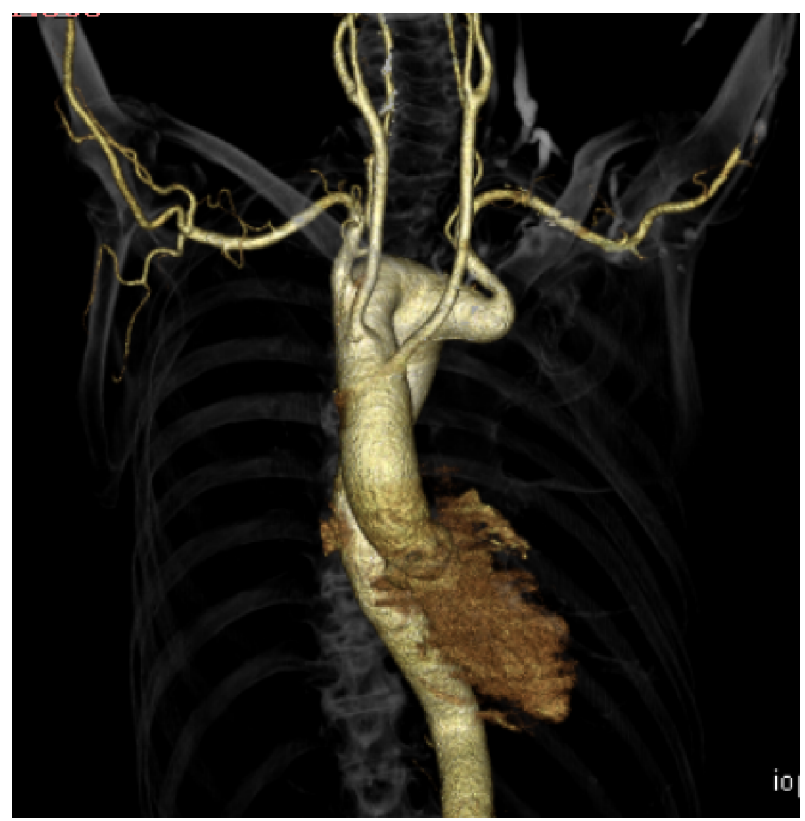

Fig. 1 Preoperative computed tomographic image showing Kommerell's diverticulum located at the origin of left subclavian artery. The maximum diameter was $33 \mathrm{~mm}$. 
8-mm, Vascutek, Scotland, UK). Then, a 6-Fr sheath was inserted in the right common carotid artery, and a hydrophilic 0.035-in guidewire (Terumo Medical Corp., Tokyo, Japan) was placed in the ascending aorta. Next, the right groin was incised to expose the femoral artery, into which an 8-Fr sheath was inserted. A 6-Fr sheath was inserted into the left femoral artery by puncture. A guiding sheath (Destination ${ }^{\circledR}$ sheath, Terumo Medical Corp., Tokyo, Japan) was introduced into the left brachial artery. A pigtail catheter was inserted in the right femoral artery. The wire was replaced with a 0.035 -in Lunderquist ${ }^{\circledR}$ wire (Cook-Europa, Bjaverskov, Denmark), and the pigtail catheter was placed in the ascending aorta. From the right femoral artery, a 24-Fr DrySeal ${ }^{\circledR}$ sheath (W. L. Gore \& Associates) was introduced, followed by a Conformable GORE TAG ${ }^{\circledR}$ stent graft. To secure the proximal landing zone, an 8-mm Cordis SMART ${ }^{\circledR}$ CONTROL $^{\circledR}$ stent (Cordis Corp., FL, USA) was introduced through the sheath that had been inserted from the right common carotid artery. The position was determined with contrast imaging to ensure the separation of cervical branches, and a Conformable GORE TAG ${ }^{\circledR}$ was deployed so that it slightly covered the right common carotid artery while the guidewire was pushing against the greater curvature. The stent was then deployed in the right common carotid artery so that half protruded into the aorta. From the destination catheter, an artery embolization coil was placed within the

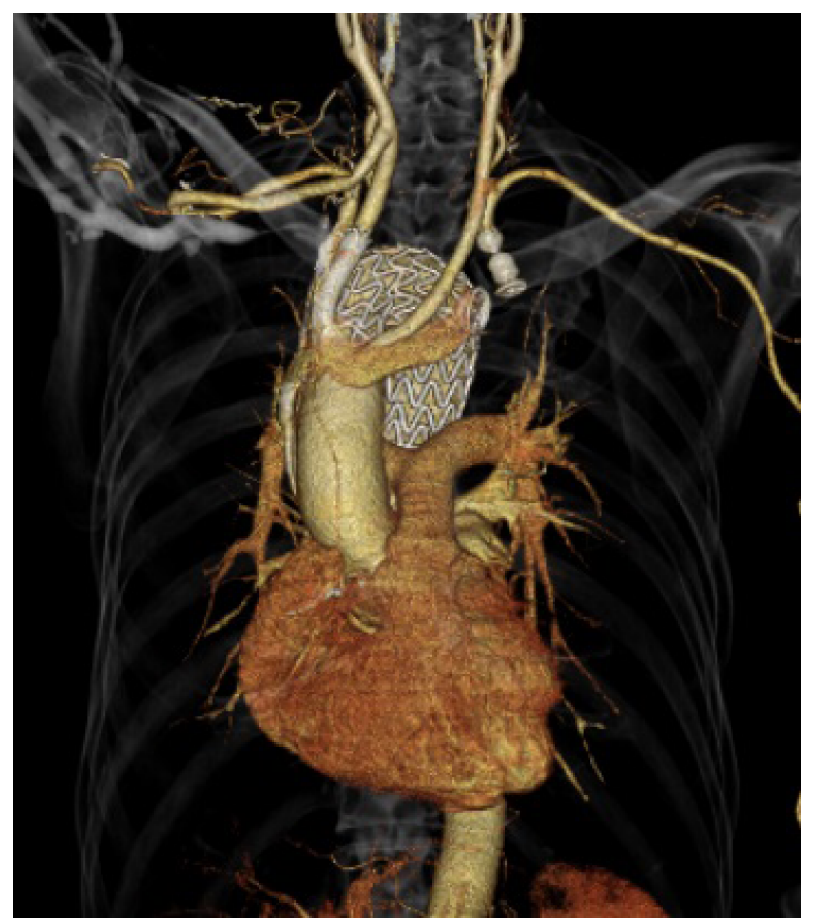

Fig. 2 Postoperative computed tomographic image showing a patent cervical artery graft with no evidence of type 1 or type 2 leakage.
Kommerell's diverticulum, followed by an Amplatzer Vascular Plug II (St. Jude Medical, MN, USA). After inflation of a Tri-Lobe balloon (W. L. Gore \& Associates), contrast imaging revealed the right common carotid artery with no delay, and showed that the right subclavian artery from the blood vessel prosthesis and the left subclavian artery from the right common carotid artery via the vertebral artery were in good condition without internal leakage into the aneurysm. After extubation, the patient was returned to the intensive care unit. The patient was discharged on day 7 following a good postoperative course. Routine postoperative CT studies have confirmed the absence of stent graft migration or leaks (Fig. 2). The swallowing difficulty resolved soon after surgery; the hoarseness disappeared about 4 months after surgery.

\section{Discussion}

Right-sided aortic arch is relatively rare, with a reported incidence of $0.1 \% .{ }^{3)}$ It has a structure that is mirror-image of the cervical vascular system. Edward type IIIa, which is often associated with concurrent congenital heart disease, and Edward type IIIb, which is characterized by anomalous branching of the subclavian artery, account for $98 \%$ of cases. Type IIIb patients may be asymptomatic or present with symptoms cause by compression of the trachea and esophagus, as in the present case. ${ }^{4)}$ Kommerell's diverticulum, which is a saccular remnant of an incompletely involuted dorsal aorta in the embryonic stage, ${ }^{5)}$ often develops into an aneurysm, and is detected only following dissection or rupture. In a review of reported cases, Cina et al. reported that $6 \%$ to $19 \%$ of Kommerell's diverticulum with a right-sided aortic arch were found following aneurysm rupture, and 53\% were found following dissection and rupture. ${ }^{6)}$ Because Kommerell's diverticulum is rare, no clear consensus has been reached as to whether surgery is indicated. As in the present case, surgical intervention is selected for patients experiencing symptoms from organ compression. Cina et al. recommended surgery for diverticula of at least $30 \mathrm{~mm}$ in diameter even without accompanying symptoms.6) Surgical options for Kommerell's diverticulum include diverticulum resection/ subclavian arterial reconstruction ${ }^{7)}$ and total arch replacement. ${ }^{8)}$ These surgical operations typically use deep hypothermic circulatory arrest, which may not necessarily ensure low surgical stress. Recently, stent grafts have been used in the treatment of Kommerell's diverticulum, and cases are occasionally reported.2,9) The anatomy of this patient included a steeply angled aortic arch and branching of Kommerell's diverticulum relatively close to the top of the aortic arch. The branching of the right subclavian artery also originated from the ascending aorta close to the top of the aortic arch. Tamiya et al. reported 
the successful placement of an open-window-type stent graft with the window in the right common carotid/right subclavian artery. ${ }^{10)}$

In our case, the aortic arch angulation and location of the cervical branch were similar to the case reported by Tamiya et al., but if stent migration were to occur massive cervical infarction would develop. We did not use their procedure because of concern that elevation of the lesser curvature side might cause a "bird's beak" and possible type 1 endoleak. ${ }^{10)}$ Furthermore, Takai et al. reported stent grafting for Kommerell's diverticulum using a common carotid artery to left subclavian artery bypass and stent graft placement via the descending aorta and not via the aortic arch. ${ }^{9)}$ In our patient, Kommerell's diverticulum branched near the aortic arch, and a procedure similar to that described Takai et al. would not have secured a sufficient proximal landing zone, thus conferring a high risk of endoleak. To secure a sufficient landing zone on the side of the lesser curvature and to prevent bird's beak, we first constructed a bypass between the right common carotid artery and the right subclavian artery using a blood vessel prosthesis. A stent graft was placed immediately after the origin of the right common carotid artery to secure an adequate landing zone. A stent was placed at the origin of the right common carotid artery to prevent potential blockage in case of stent graft migration toward the proximal side. In this patient, we inserted the stent through the right common carotid artery before stent graft placement. We think this technique is slightly more likely to prevent migration, to secure an adequate proximal landing zone and to secure a landing zone for insertion of additional devices in case of a type $1 \mathrm{a}$ endoleak. Because of the right-side dominance of the vertebral artery, the right-handedness of the patient, and an adequate neural network on both sides as confirmed by preoperative head magnetic resonance angiography, we used blood flow from the vertebral artery to feed the left subclavian artery. In case of a postoperative type 1a endoleak over an extended period, a stent graft can be placed in the proximal aorta in addition to the stent in the right common carotid artery. The conformable GORE TAG ${ }^{\circledR}$, which was used in this patient, is a third-generation device with improved contact on the lesser curvature side. Because the device was not subject to the limitation posed by the aortic angle, it allowed for a successful stent graft placement in the steep-angled aorta without causing endoleak. In this patient, we inserted the stent graft beyond aortic arch, which differs from other reports. The aortic arch angulation in this patient was less than 30 degrees, which is steep compared with other cases. However, the conformable GORE TAG $^{\circledR}$ fit gently without leakage and bird's beak. That device seemed to be suitable for use in cases like this one.

Owing to the limited number of cases, no operative pro- cedure has been established as standard for Kommerell's diverticulum. We consider that accurate three-dimensional CT measurements and appropriate cervical debranching ensure minimally invasive stent grafting.

\section{Conclusion}

Endovascular repair with debranching for Kommerell's diverticulum was safe and effective, avoiding the need for a more complex procedure.

\section{Acknowledgments}

None.

\section{Disclosure Statement}

None.

\section{Author Contributions}

Final approval of the article: all authors

\section{References}

1) Tsukube T, Ataka K, Sakata M, et al. Surgical treatment of an aneurysm in the right aortic arch with aberrant left subclavian artery. Ann Thorac Surg 2001; 17: 1710-1.

2) Kamihara S, Yamauchi M, Kitano T. Debranching and endovascular repair for Kommerell's diverticulum involving right-sided aortic arch with mirror image branching. Jpn J Cardiovasc Surg 2014; 43: 322-5.

3) Hastreiter AR, D'Cruz IA, Cantez T, et al. Right-sided aorta. Br Heart J 1966; 28: 722-39.

4) Yano M, Shiozaki H, Murata A, et al. Successful resection of thoracic esophageal cancer associated with the right aortic arch. Surg Today 1998; 28: 76-8.

5) Van Son JA, Konstantinov IE. Kommerell and Kommerell's diverticulum. Tex Heart Inst J 2002; 29: 109-12.

6) Cina CS, Althani H, Pasenau J, et al. Kommerell's diverticulum and right-sided aortic arch: a cohort study and review of the literature. J Vasc Surg 2004; 39: 131-9.

7) Backer CL, Hillman N, Mavroudis C, et al. Resection of Kommerell's diverticulum and left subclavian artery transfer for recurrent symptoms after vascular ring division. Eur J Cardiothorac Surg 2002; 22: 64-9.

8) Mieno S, Ozawa H, Daimon M, et al. Surgical treatment for Kommerell diverticulum. Jpn J Cardiovasc Surg 2011; 40: 144-9.

9) Takai H, Kawaguchi S, Yamabe T, et al. Successful 36 months result of debranching TEVAR for Kommerell's diverticulum with the aberrant left subclavian artery. Vasc Med Surg 2015; 3: 203.

10) Tamiya Y, Fukada J, Fuzisawa Y, et al. Endovascular repair with a fenestrated stent graft for Kommerell's diverticulum with a right aortic arch. Jpn J Cardiovasc Surg 2013; 42: 151-4. 